\title{
Resveratrol attenuates hydrogen peroxide-induced apoptosis, reactive oxygen species generation, and PSGL-1 and VWF activation in human umbilical vein endothelial cells, potentially via MAPK signalling pathways
}

\author{
ZHENKAI LOU ${ }^{1 *}$, XINGGUO LI ${ }^{1 *}$, XUELING ZHAO ${ }^{1}$, KAILI DU ${ }^{1}$, XING $^{2}$ and BING WANG ${ }^{1}$ \\ Departments of ${ }^{1}$ Orthopaedics and ${ }^{2}$ Ultrasound, The First Affiliated Hospital of \\ Kunming Medical University, Kunming, Yunnan 650032, P.R. China
}

Received March 27, 2017; Accepted October 24, 2017

DOI: $10.3892 / \mathrm{mmr} .2017 .8124$

\begin{abstract}
Reactive oxygen species (ROS) are implicated in the pathogenesis of thrombosis. Studies have reported that resveratrol exhibits antioxidative activities, however, the effect and underlying mechanisms of resveratrol on venous thrombosis remain largely unknown. To investigate the effect of resveratrol on venous thrombosis and the underlying mechanisms, the present study investigated the effects of resveratrol on cell viability, apoptosis, ROS generation and the expression of thrombosis-associated markers in human umbilical vein endothelial cells (HUVECs). HUVECs were pretreated with resveratrol for $2 \mathrm{~h}$ and incubated with hydrogen peroxide $\left(\mathrm{H}_{2} \mathrm{O}_{2}\right)$ for $24 \mathrm{~h}$ prior to the evaluation of cell viability, ROS generation, apoptosis and thrombosis-associated marker expression by performing MTT assays, 2',7'-dichlorofluorescin diacetate reagent, flow cytometry, and reverse transcription-quantitative polymerase chain reaction (RT-qPCR) and western blot analysis, respectively. Subsequently, to validate whether resveratrol functions via mitogen-activated protein kinase (MAPK) pathways, the expression of thrombosis-associated
\end{abstract}

Correspondence to: Professor Bing Wang, Department of Orthopaedics, The First Affiliated Hospital of Kunming Medical University, 295 Xichang Road, Kunming, Yunnan 650032, P.R. China

E-mail: wangbing700219@163.com

"Contributed equally

Abbreviations: DVT, deep venous thrombosis; ROS, reactive oxygen species; HUVECs, human umbilical vein endothelial cells; ECs, endothelial cells; ERK, extracellular signal-regulated kinase; c-Jun, c-Jun N-terminal kinase; MAPK, mitogen-activated protein kinase; VWF, von Willebrand factor; PSGL-1, P-selectin glycoprotein ligand-1

Key words: resveratrol, reactive oxygen species, apoptosis, thrombosis-associated markers, mitogen-activated protein kinase signalling pathway markers was detected by western blot analysis and RT-qPCR following treatment of cells with resveratrol and the MAPK pathway activators anisomycin and curcumin. The results demonstrated that cell viability was markedly reduced by $\mathrm{H}_{2} \mathrm{O}_{2}$, and resveratrol treatment reversed the reductions in cell viability in a dose-dependent manner. In addition, the levels of cell apoptosis and ROS generation were significantly increased by $\mathrm{H}_{2} \mathrm{O}_{2}$ alone, and resveratrol also reduced these effects in a dose-dependent manner. Furthermore, the mRNA and protein expression of caspase-3, P-selectin glycoprotein ligand-1 and von Willebrand factor was upregulated by $\mathrm{H}_{2} \mathrm{O}_{2}$ treatment in HUVECs. However, resveratrol decreased the protein expression these proteins in a dose-dependent manner. Resveratrol also significantly inhibited the induction of phosphorylated (p)-p38, P-c-Jun N-terminal kinase and P-extracellular signal-regulated kinase by $\mathrm{H}_{2} \mathrm{O}_{2}$, and these effects were attenuated by the MAPK pathway activators anisomycin and curcumin. In conclusion, these results indicate that resveratrol protected HUVECs against oxidative stress and apoptosis. Furthermore, to the best of our knowledge, the present study is the first to demonstrate that resveratrol attenuates the expression of thrombosis-associated markers induced by $\mathrm{H}_{2} \mathrm{O}_{2}$, which may occur through the suppression of the MAPK signalling pathways, indicating a potential novel therapeutic approach to prevent venous thrombosis.

\section{Introduction}

Deep venous thrombosis (DVT) is a global health problem that affects 1 in 1,000 individuals according to epidemiological studies (1). Even with preventive measures, the incidence of DVT ranges from 2.22-3.29\% among patients undergoing major orthopaedic surgeries in developed countries $(2,3)$. Pulmonary embolism, the most dangerous compilation of DVT, affects between 500,000 and 700,000 patients, which may cause mortality in $10-15 \%$ of these patients (4). Structural and functional disorders of venous endothelial cells (ECs) have an initial role in the pathogenesis and progression of DVT (5). Currently, oxidative stress injury, which occurs during hypoxia, sepsis and ischaemia-reperfusion injury, is considered to lead to EC dysfunction and initiation of the 
coagulation cascade (6,7). Excessive levels of reactive oxygen species (ROS) cause oxidative damage to ECs and subsequently activate platelets and leukocytes, increasing their adhesion and aggregation ability and triggering procoagulant reactions $(8,9)$. Therefore, the hypothesis of adopting antioxidants to prevent vascular embolism diseases has been proposed and proven effective in several studies (10-12).

Resveratrol (trans-3,4,5-trihydroxystilbene), a natural, plant-derived polyphenolic compound that is abundant in grape skin, peanuts, mulberries and red wine, has been proven to exhibit a wide range of pharmacological activities, including antioxidant activity, lipoprotein metabolism modulation, anti-platelet aggregation, and anti-inflammatory and anti-tumour effects (13). In addition, cardioprotective activities of resveratrol have previously been identified, however, studies have primarily focused on cardiac and arterial diseases $(14,15)$. Whether resveratrol may exhibit inhibitory effects on venous thrombosis remains largely unknown. Pathways that have previously been associated with the effects of resveratrol treatment include AMP-activated protein kinase, phosphatidylinositol 3-kinase/Akt and sirtuin $1(16,17)$. Extracellular signal-regulated kinase (ERK), c-Jun N-terminal kinase (c-Jun) and p38 mitogen-activated protein kinase (MAPK) are conventional MAPK signalling pathway families that are implicated in various diseases, including tumour growth and haemostasis, among others. Furthermore, MAPK signalling pathways, which promote apoptosis and have roles in venous endothelial oxidative stress injury, have been confirmed as important targets that promote thrombosis by mediating interactions among venous endothelial cells, leukocytes and platelets (18). The present study hypothesises that MAPKs may be involved in mediating the effects of resveratrol on venous thrombosis. In addition, von Willebrand factor (VWF) and P-selectin glycoprotein ligand-1 (PSGL-1) are considered thrombotic risk markers, with increases in these factors indicating a thrombotic phenotype $(19,20)$. Therefore, the present study investigated VWF and PSGL-1 levels in HUVECs following different treatments.

The present study aimed to investigate the effects of resveratrol on apoptosis, ROS generation and the expression of thrombosis-associated markers (VWF and PSGL-1) induced by hydrogen peroxide $\left(\mathrm{H}_{2} \mathrm{O}_{2}\right)$ in addition to the underlying mechanisms, in vitro. The results of the present study indicated that resveratrol may exert antithrombotic activity in vitro by inactivating MAPK signalling pathways.

\section{Materials and methods}

Reagents, chemicals and antibodies. Primary human umbilical vein endothelial cells (HUVECs) were purchased from CHI Scientific, Inc. (Maynard, MA, USA). High-glucose Dulbecco's modified Eagle's medium (DMEM) and fetal bovine serum (FBS) were both purchased from Hyclone (GE Healthcare Life Sciences, Logan, UT, USA). Resveratrol (purity $>99.0 \%$ ) was purchased from Tokyo Chemical Industry Co., Ltd. (Tokyo, Japan). All primary antibodies were purchased from Proteintech Group, Inc. (Chicago, IL, USA). Phosphorylated antibodies were purchased from ABclonal, Inc. (Cambridge, MA, USA). Anisomycin and curcumin were purchased from Beijing TOP Science Biotechnology Co., Ltd. (Beijing,
China). The MTT kit, dimethyl sulphoxide (DMSO), and 2',7'-dichlorofluorescin diacetate (DCFH-DA) were purchased from Sigma-Aldrich; Merck KGaA (Darmstadt, Germany). The Annexin V-fluorescein isothiocyanate (FITC)/propidium iodide (PI) double-staining Apoptosis Detection kit was obtained from Beyotime Institute of Biotechnology (Haimen, China). Reverse transcription-quantitative polymerase chain reaction (RT-qPCR) primers were synthesized by Sangon Biotech Co., Ltd. (Shanghai, China).

Cell culture and treatments. HUVECs were cultured in DMEM medium supplemented with $10 \%$ FBS, $100 \mathrm{U} / \mathrm{ml}$ penicillin and $100 \mu \mathrm{g} / \mathrm{ml}$ streptomycin. Cells were maintained at $37^{\circ} \mathrm{C}$ with $5 \% \mathrm{CO}_{2}$ in a humidified atmosphere. Cells were digested with $0.25 \%$ trypsin, centrifuged and harvested in a centrifuge (150 x g at room temperature for $5 \mathrm{~min}$ ) and resuspended in DMEM medium. The cell concentration was adjusted to $1 \times 10^{4}$ cells $/ \mathrm{ml}$ and cells were inoculated into a culture flask. The resveratrol solution was prepared in DMSO and diluted with culture medium immediately prior to use. DMSO was used as the control group. The cells were pretreated at $37^{\circ} \mathrm{C}$ with resveratrol $(0,10,20$ and $30 \mu \mathrm{M})$ for $2 \mathrm{~h}$ and were then subjected to $\mathrm{H}_{2} \mathrm{O}_{2}(200 \mu \mathrm{M})$ for $24 \mathrm{~h}$. In addition, in the MTT assay, one group received treatment with $30 \mu \mathrm{M}$ resveratrol without $\mathrm{H}_{2} \mathrm{O}_{2}$ treatment. Control cells were treated with medium alone. After the treatments were performed, the cells were harvested for further analysis.

Analysis of cell viability. The viability of HUVECs treated with $0,10,20$ and $30 \mu \mathrm{M}$ resveratrol for $2 \mathrm{~h}$ followed by treatment with or without $200 \mu \mathrm{M} \mathrm{H}_{2} \mathrm{O}_{2}$ for $24 \mathrm{~h}$ was assessed with an MTT assay. After cells were treated and washed with PBS, $10 \mu \mathrm{l}$ MTT solution $(5 \mathrm{mg} / \mathrm{ml})$ was added to the cells. The samples were incubated for $4 \mathrm{~h}$ at $37^{\circ} \mathrm{C}$ and $100 \mu \mathrm{l}$ dimethyl sulfoxide was added to each well to dissolve the formazan crystals for $4 \mathrm{~h}$ at $37^{\circ} \mathrm{C}$. The plates were read at $570 \mathrm{~nm}$ using a microplate reader (Bio-Rad Laboratories, Inc., Hercules, CA, USA) and the cell viability was expressed as the optical density (OD) value.

Cellular apoptosis assay. HUVECs that were treated with 0 , 10,20 and $30 \mu \mathrm{M}$ resveratrol for $2 \mathrm{~h}$ followed by treatment with or without $\mathrm{H}_{2} \mathrm{O}_{2}$ for $24 \mathrm{~h}$ were double stained using an Annexin V-FITC/PI Apoptosis Detection kit, according to the manufacturer's instructions. Briefly, the cells were washed and collected in a $1.5 \mathrm{ml}$ tube, $1 \times 10^{5}-1 \times 10^{6}$ cells were resuspended in $300 \mu \mathrm{l} 1 \mathrm{X}$ binding buffer and cells were transferred to a sterile flow cytometry glass tube. Annexin V-FITC ( $5 \mu \mathrm{l})$ was added and the tubes were incubated in the dark for $30 \mathrm{~min}$ at room temperature. Subsequently, cells were incubated in the dark with $5 \mu \mathrm{l} \mathrm{PI}$ at room temperature for $15 \mathrm{~min}$ and analysed with a flow cytometer (Sysmex Partec GmbH, Gorlitz, Germany) and FloMax ${ }^{\circledR}$ software version 2.7 (Sysmex Partec GmbH).

Measurement of intracellular ROS. Intracellular ROS levels were evaluated using the DCFH-DA fluorescent probe reagent and a flow cytometer, according to the manufacturer's instructions. Briefly, after cells $\left(1 \times 10^{5}\right)$ were seeded in 6-well plates and treated with $0,10,20$ and $30 \mu \mathrm{M}$ resveratrol for $2 \mathrm{~h}$ followed by treatment with or without $\mathrm{H}_{2} \mathrm{O}_{2}$ for $24 \mathrm{~h}$, the cells were washed with PBS and incubated with DCFH-DA 
$(10 \mu \mathrm{M})$ in DMEM medium without FBS at $37^{\circ} \mathrm{C}$ for $20 \mathrm{~min}$. Following incubation, the cellular 2'7'-dichlorofluorescein (DCF) green fluorescence in each well was subsequently imaged at $488 \mathrm{~nm}$ using a fluorescence microscope at x200 magnification (Olympus Corporation, Tokyo, Japan), and DCF fluorescence was quantified using Image-Pro Plus 6 software (Media Cybernetics, Inc., Rockville, MD, USA). Subsequently, flow cytometry (Sysmex Partec GmbH) and FloMax ${ }^{\circledR}$ software version 2.7 (Sysmex Partec GmbH) was also performed to quantify DCF fluorescence and measure ROS generation.

Western blot analysis. Cells were treated at $37^{\circ} \mathrm{C}$ with 0 , 10,20 and $30 \mu \mathrm{M}$ resveratrol for $2 \mathrm{~h}$ followed by treatment with or without $\mathrm{H}_{2} \mathrm{O}_{2}$ for $24 \mathrm{~h}$. For experiments including anisomycin/curcumin treatment, cells were treated with resveratrol $(0$ and $30 \mu \mathrm{M})$ for $2 \mathrm{~h}$ followed by treatment with or without anisomycin $(0.4 \mu \mathrm{g} / \mathrm{ml}$ for $6 \mathrm{~h})$ or curcumin $(25 \mu \mathrm{M}$ for $4 \mathrm{~h}$ ) prior to treatment with $200 \mu \mathrm{M} \mathrm{H}_{2} \mathrm{O}_{2}$ for $24 \mathrm{~h}$. Cells were homogenized in radioimminoprecipitation assay buffer (Beyotime Institute of Biotechnology). The lysates were centrifuged $(10,625 \mathrm{x} g$ at room temperature for $5 \mathrm{~min})$ and the protein supernatant was collected. Protein concentrations were determined using a BCA Protein assay kit (Beyotime Institute of Biotechnology). The proteins $(30 \mu \mathrm{g})$ were separated by $10 \%$ SDS-PAGE and transferred to nitrocellulose membranes. The membranes were blocked with $5 \%$ nonfat dry milk in Tris-buffered saline and $0.1 \%$ Tween-20 (TBS-T, pH 7.6) at room temperature for $2 \mathrm{~h}$ and probed with antibodies (at 1:1,000) against phosphorylated (p)-p38 MAPK (cat. no. AP0297), p38 MAPK (cat. no. 14064-1-AP), P-c-Jun (cat. no. AP0048), c-Jun (cat. no. 24909-1-AP), P-ERK (cat. no. AP0472), ERK (cat. no. 16443-1-AP), PSGL-1 (cat. no. 23605-1-AP), VWF (cat. no. 11778-1-AP), caspase-3 (cat. no. 19677-1-AP) and $\beta$-actin (cat. no. 60008-1-AP) at $4^{\circ} \mathrm{C}$ overnight. The membranes were washed with TBS-T and hybridized with secondary goat anti-mouse (cat. no. sc-2039) or goat anti-rabbit (cat. no. sc-2007) horse radish peroxidase antibodies at 1:2,000 dilution (Santa Cruz Biotechnology, Inc., Dallas, TX, USA) for $2 \mathrm{~h}$ at room temperature and washed again with TBS-T. The protein bands were developed using an ECL Western Blotting substrate (Pierce; Thermo Fisher Scientific, Inc., Waltham, MA, USA) and exposed to autoradiography film (Bio-Rad Laboratories, Inc.) for visualization of the bands. $\beta$-actin was used as a loading control. The results were quantified using ImageJ software version 1.48 (National Institutes of Health, Bethesda, MD, USA). The results for the control group were defined as $100 \%$.

$R T-q P C R$ assay. Cells were treated at $37^{\circ} \mathrm{C}$ with resveratrol $(0$ and $30 \mu \mathrm{M}$ ) for $2 \mathrm{~h}$ followed by treatment with or without $200 \mu \mathrm{M}$ $\mathrm{H}_{2} \mathrm{O}_{2}$ for $24 \mathrm{~h}$. For experiments including anisomycin/curcumin treatment, cellswere treated with resveratrol $(0$ and $30 \mu \mathrm{M})$ for $2 \mathrm{~h}$ followed by treatment with or without anisomycin $(0.4 \mu \mathrm{g} / \mathrm{ml}$ for $6 \mathrm{~h}$ ) or curcumin ( $25 \mu \mathrm{M}$ for $4 \mathrm{~h}$ ) prior to treatment with $200 \mu \mathrm{M} \mathrm{H}_{2} \mathrm{O}_{2}$ for $24 \mathrm{~h}$. Total RNA was isolated from HUVECs using TRIzol reagent (Takara Biotechnology Co., Ltd., Dalian, China) according to the manufacturer's instructions. The integrity of the RNA samples was evaluated using agarose gel electrophoresis. Total RNA was reverse transcribed into

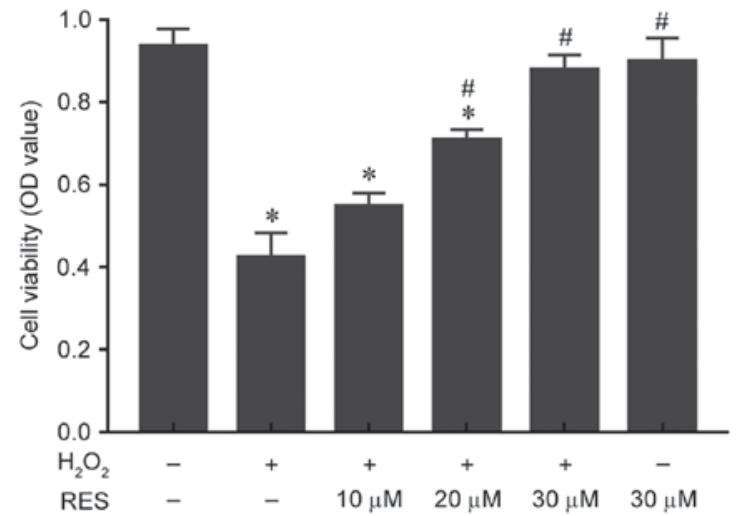

Figure 1. Resveratrol rescues cell viability in $\mathrm{H}_{2} \mathrm{O}_{2}$-treated HUVECs. HUVECs were exposed to $0,10,20$ and $30 \mu \mathrm{M}$ resveratrol for $2 \mathrm{~h}$ prior to treatment with $200 \mu \mathrm{M} \mathrm{H}_{2} \mathrm{O}_{2}$ for $24 \mathrm{~h}$. Cell viability was assessed with an MTT assay. Data are presented as the mean \pm standard error of the mean from six independent experiments, each performed in triplicate. ${ }^{*} \mathrm{P}<0.05$ vs. control; ${ }^{\#} \mathrm{P}<0.05$ vs. $\mathrm{H}_{2} \mathrm{O}_{2}$ only group. $\mathrm{H}_{2} \mathrm{O}_{2}$, hydrogen peroxide; HUVECs, human umbilical vein endothelial cells; OD, optical density; RES, resveratrol.

cDNA using an PrimeScript ${ }^{\mathrm{TM}}$ RT Master mix kit, followed by SYBR $^{\circledR}$ Premix Ex Taq ${ }^{\mathrm{TM}}$ II (both from Takara Biotechnology Co., Ltd.) to detect the expression levels. $\beta$-actin was used as an internal control. The thermocycling conditions were as follows: Thirty seconds at $95^{\circ} \mathrm{C}$ for the activation of Taq DNA polymerase, followed by 40 cycles of amplification at $95^{\circ} \mathrm{C}$ for $15 \mathrm{sec}$ and $60^{\circ} \mathrm{C}$ for $1 \mathrm{~min}$. The reactions were performed in triplicate. The specific primers used for qPCR were as follows: Caspase-3, 5'-GGGCCTGTTGAACTGAAAAA-3' (forward) and 5'-CCGTCCTTTGAATTTCTCCA-3' (reverse); PSGL-1, 5'-ATGATTTCCTGCCAGAAACG-3' (forward) and 5'-GTG GTCAGCTCTGTGACTGC-3' (reverse); VWF, 5'-TCCTCC TACTCTGCCCCCC-3' (forward) and 5'-TCCATCCGCTGA ATCACCTC-3' (reverse); $\beta$-actin, 5'-ACGGCAAGTTCAA CGGCACAG-3' (forward) and 5'-GACGCCAGTAGACTC CACGACA-3' (reverse); p38, 5'-GGGGCAGATCTGAAC AACAT-3' (forward) and 5'-CAGGAGCCCTGTACCACC TA-3' (reverse); ERK, 5'-TGATCACACAGGGTTCCTGA-3' (forward) and 5'-TGGAAAGATGGGCCTGTTAG-3' (reverse); and c-Jun, 5'-ACAGAGCATGACCCTGAACC-3' (forward) and 5'-CCATTFCTGGACTGGATTAT-3' (reverse). Gene expression values were calculated and normalized to $\beta$-actin expression using the $2^{-\Delta \Delta \mathrm{Cq}}$ relative expression method (21).

Statistical analysis. Data are presented as the mean \pm standard deviation. Group comparisons were assessed using one-way analysis of variance followed by Tukey's post hoc test using GraphPad Prism 5.0a (GraphPad Software, Inc., La Jolla, CA, USA). $P<0.05$ was considered to indicate a statistically significant difference.

\section{Results}

Resveratrol protects $\mathrm{HUVECS}$ from $\mathrm{H}_{2} \mathrm{O}_{2}$-induced injury. HUVECs were pretreated with resveratrol for $2 \mathrm{~h}$ and incubated with $\mathrm{H}_{2} \mathrm{O}_{2}$ for $24 \mathrm{~h}$, and cell viability was measured with an MTT assay. The viability of cells was decreased significantly by treatment with $200 \mu \mathrm{M} \mathrm{H}_{2} \mathrm{O}_{2}$ for $24 \mathrm{~h}$, compared with the control group $(\mathrm{P}<0.05$; Fig. 1), while 
A

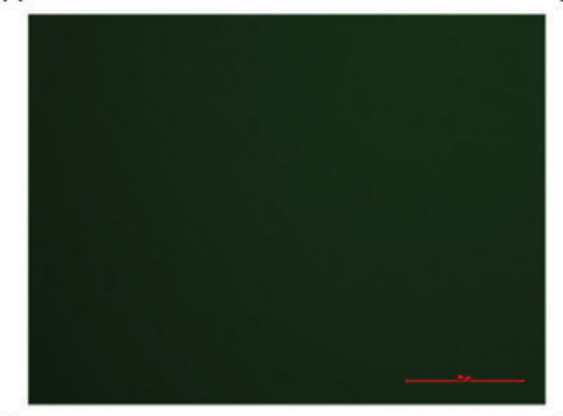

D

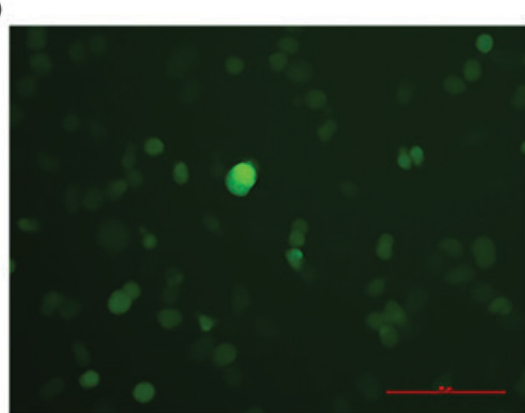

G

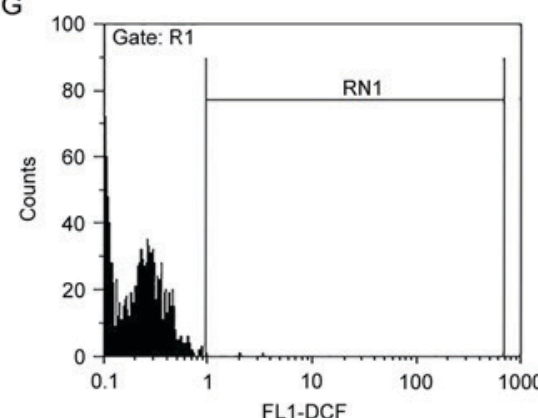

$J$

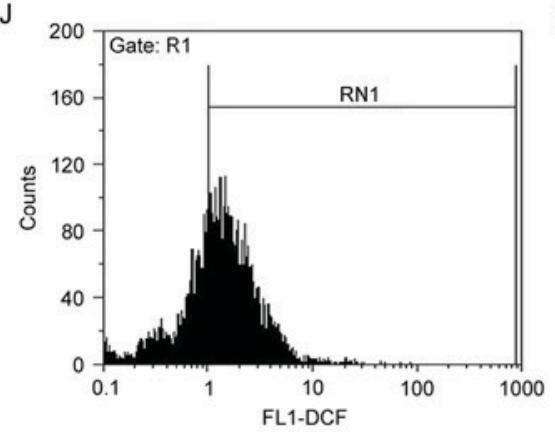

B
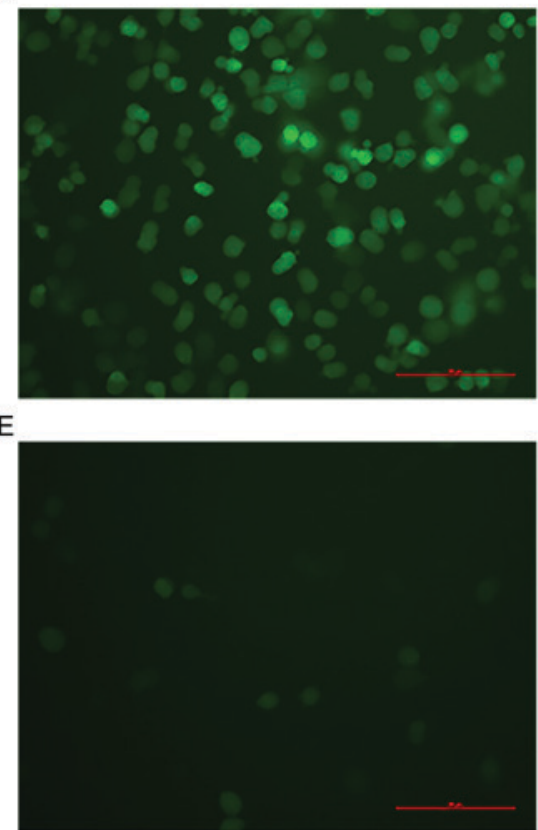

$\mathrm{H}$

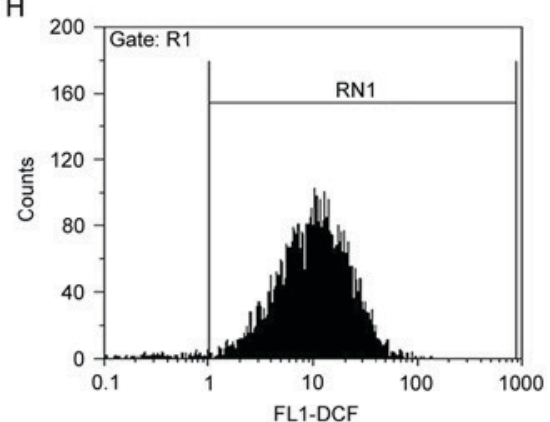

$\mathrm{K}$

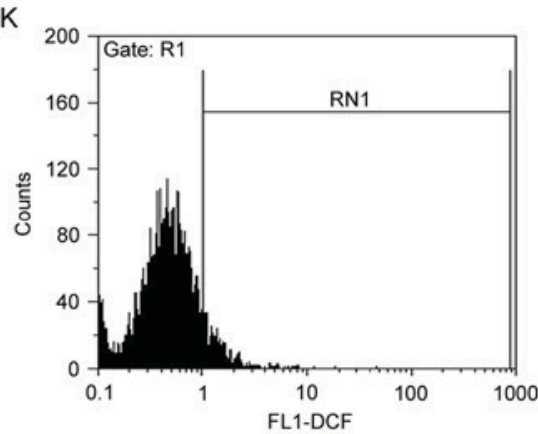

$\mathrm{C}$
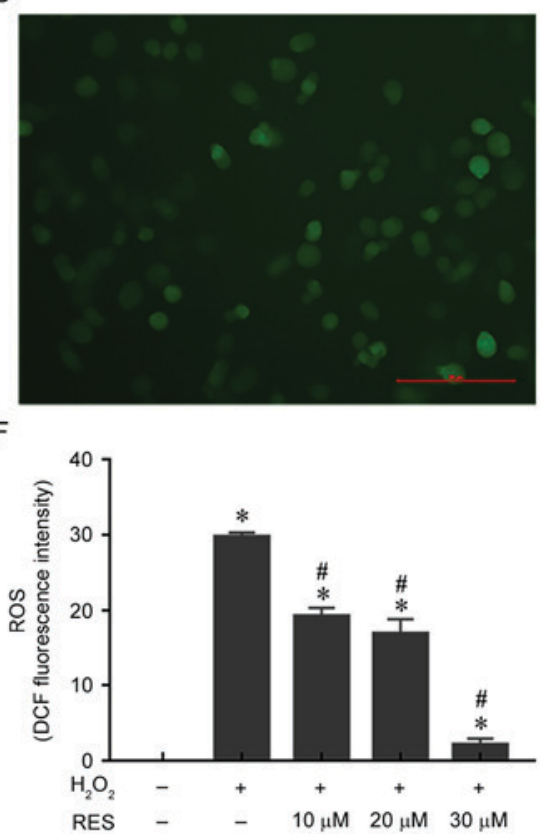

I

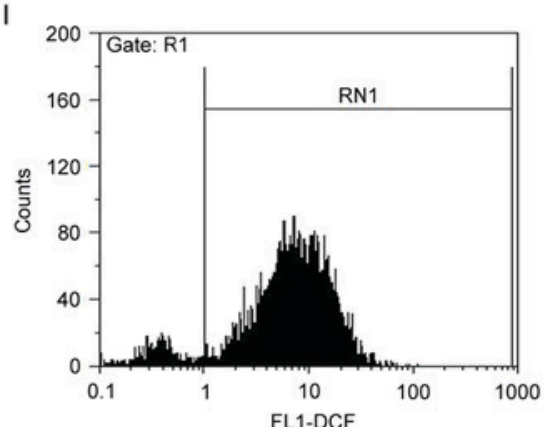

$\mathrm{L}$

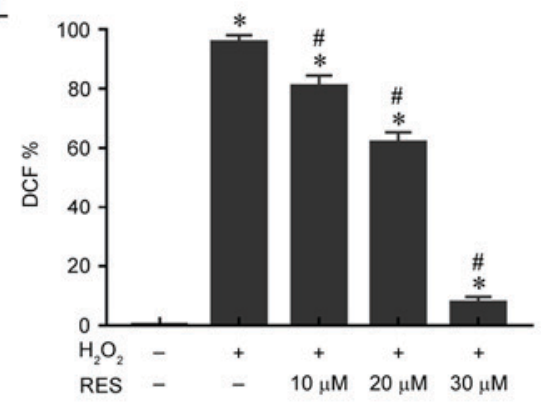

Figure 2. Resveratrol ameliorates $\mathrm{H}_{2} \mathrm{O}_{2}$-induced ROS generation in HUVECs. Representative micrographs of HUVECs stained with DCF in (A) control, (B) $200 \mu \mathrm{M} \mathrm{H}_{2} \mathrm{O}_{2}$, (C) $200 \mu \mathrm{M} \mathrm{H}_{2} \mathrm{O}_{2}+10 \mu \mathrm{M}$ resveratrol, (D) $200 \mu \mathrm{M} \mathrm{H}_{2} \mathrm{O}_{2}+20 \mu \mathrm{M}$ resveratrol and (E) $200 \mu \mathrm{M} \mathrm{H}_{2} \mathrm{O}_{2}+30 \mu \mathrm{M}$ resveratrol groups, as visualized under a fluorescence microscope at x200 magnification. Scale bar, $100 \mu \mathrm{m}$. (F) Quantification of DCF fluorescence in micrographs using Image-Pro Plus 6.0 software. DCF fluorescence was also quantified by flow cytometry. Representative flow cytometry plots for HUVECs stained with DCF in (G) control, (H) $200 \mu \mathrm{M} \mathrm{H}_{2} \mathrm{O}_{2}$, (I) $200 \mu \mathrm{M} \mathrm{H}_{2} \mathrm{O}_{2}+10 \mu \mathrm{M}$ resveratrol, (J) $200 \mu \mathrm{M} \mathrm{H}_{2} \mathrm{O}_{2}+20 \mu \mathrm{M}$ resveratrol and (K) $200 \mu \mathrm{M} \mathrm{H} \mathrm{O}_{2}+30 \mu \mathrm{M}$ resveratrol groups. (L) Statistical results of flow cytometry. ${ }^{*} \mathrm{P}<0.05$ vs. control; ${ }^{\#} \mathrm{P}<0.05$ vs. $\mathrm{H}_{2} \mathrm{O}_{2}$ only group. $\mathrm{H}_{2} \mathrm{O}_{2}$, hydrogen peroxide; ROS, reactive oxygen species; HUVECs, human umbilical vein endothelial cells; DCF, dichlorofluorescein; RES, resveratrol.

resveratrol protected cells from $\mathrm{H}_{2} \mathrm{O}_{2}$-induced injury in a concentration-dependent manner $(10 \mu \mathrm{M}, 0.55 \pm 0.03 \mathrm{OD}$; $20 \mu \mathrm{M}, 0.71 \pm 0.02 \mathrm{OD}$; and $30 \mu \mathrm{M}, 0.88 \pm 0.04$ OD; Fig. 1). Resveratrol significantly enhanced cell viability at 20 and $30 \mu \mathrm{M}$ compared with the $\mathrm{H}_{2} \mathrm{O}_{2}$ only group $(\mathrm{P}<0.05)$, while resveratrol treatment alone exhibited no cytotoxicity compared with the control group $(\mathrm{P}>0.05)$. These results indicate that resveratrol may protect HUVECs from $\mathrm{H}_{2} \mathrm{O}_{2}$-induced injury/death.
Resveratrol attenuates $\mathrm{H}_{2} \mathrm{O}_{2}$-induced $\mathrm{ROS}$ production in HUVECs. ROS are considered indicators of the cellular oxidative stress state. Therefore, intracellular ROS accumulation was determined by measuring DCF-derived fluorescence with the DCFH-DA probe. The results demonstrated that $\mathrm{H}_{2} \mathrm{O}_{2}$ significantly increased ROS levels compared with the control group $(\mathrm{P}<0.05)$ and that resveratrol significantly decreased ROS levels in a concentration-dependent manner compared with the $\mathrm{H}_{2} \mathrm{O}_{2}$ only group (Fig. 2A-F). The DCF fluorescence 

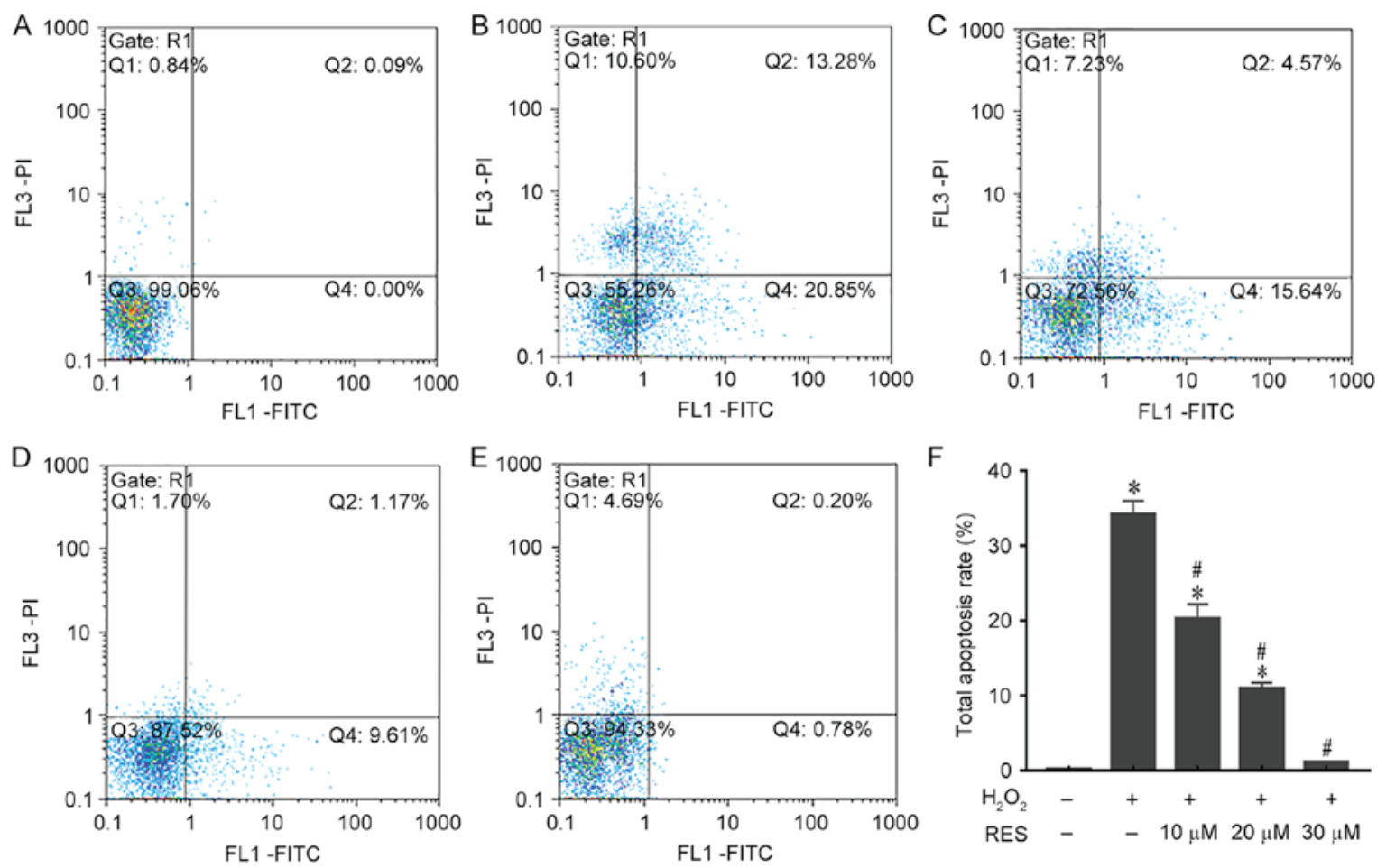

Figure 3. Resveratrol reduces $\mathrm{H}_{2} \mathrm{O}_{2}$-induced apoptosis of HUVECs. The percentage of apoptotic cells was quantified by Annexin V-PI labelling and flow cytometry analysis. Representative flow cytometry plots indicating apoptosis levels in HUVECs in (A) control, (B) $200 \mu \mathrm{M} \mathrm{H}_{2} \mathrm{O}_{2}$, (C) $200 \mu \mathrm{M} \mathrm{H} \mathrm{O}_{2}+10 \mu \mathrm{M}$ resveratrol, (D) $200 \mu \mathrm{M} \mathrm{H}_{2} \mathrm{O}_{2}+20 \mu \mathrm{M}$ resveratrol and (E) $200 \mu \mathrm{M} \mathrm{H}_{2} \mathrm{O}_{2}+30 \mu \mathrm{M}$ resveratrol groups. Quadrants 2 and 4 were considered to indicate apoptotic cells. (F) The apoptosis ratio was statistically analysed and presented in a histogram. ${ }^{*} \mathrm{P}<0.05$ vs. control; ${ }^{*} \mathrm{P}<0.05$ vs. $\mathrm{H}_{2} \mathrm{O}_{2}$ only group. $\mathrm{H}_{2} \mathrm{O}_{2}$ only group. $\mathrm{H}_{2} \mathrm{O}_{2}$, hydrogen peroxide; HUVECs, human umbilical vein endothelial cells; PI, propidium iodide; RES, resveratrol; FITC, fluorescein isothiocyanate; Q, quadrant.

quantification results obtained by flow cytometry and presented in Fig. 2G-L were consistent with the micrographs. These results indicate that resveratrol may attenuate $\mathrm{H}_{2} \mathrm{O}_{2}$-induced ROS production and oxidative stress in HUVECs.

Resveratrol reduces $\mathrm{H}_{2} \mathrm{O}_{2}$-induced apoptosis in HUVECs. To quantitatively investigate the anti-apoptotic effects of resveratrol in $\mathrm{H}_{2} \mathrm{O}_{2}$-treated HUVECs, cell apoptosis was measured by Annexin V/PI staining. Quadrants 2 and 4 were considered to indicate apoptotic cells. As demonstrated in Fig. 3, HUVEC apoptosis increased to $34.19 \pm 1.8 \%$ ( $\mathrm{P}<0.05$ vs. control group) when exposed to $\mathrm{H}_{2} \mathrm{O}_{2}$. By contrast, increasing doses of resveratrol clearly reduced the apoptosis of HUVECs to 20.24 \pm 1.95 , $10.93 \pm 0.77$ and $1.03 \pm 0.05 \%\left(\mathrm{P}<0.05\right.$ vs. $\mathrm{H}_{2} \mathrm{O}_{2}$ only group $)$. These results indicate that resveratrol may prevent apoptosis induced by $\mathrm{H}_{2} \mathrm{O}_{2}$.

Resveratrol inhibits the activation of caspase-3, PSGL-1 and VWF induced by $\mathrm{H}_{2} \mathrm{O}_{2}$. Caspase-3 is a key mediator of cell death and an executioner for the death programme in cells in response to $\mathrm{H}_{2} \mathrm{O}_{2}$. PSGL-1 and VWF are markers of a prothrombotic status and predict the occurrence of thrombosis. As demonstrated in Fig. 4A and B by western blotting results, the protein expression of caspase- 3 was significantly increased by $\mathrm{H}_{2} \mathrm{O}_{2}$ treatment compared with the control group $(\mathrm{P}<0.05)$. However, when cells were pretreated with resveratrol for $2 \mathrm{~h}$ prior to incubation with $\mathrm{H}_{2} \mathrm{O}_{2}$, caspase-3 protein expression was significantly decreased in a concentration-dependent manner compared with the $\mathrm{H}_{2} \mathrm{O}_{2}$ only group $(\mathrm{P}<0.05)$. The protein levels of PSGL-1 and VWF were also significantly increased by $\mathrm{H}_{2} \mathrm{O}_{2}$ compared with the control group $(\mathrm{P}<0.05)$, while PSGL-1 and VWF protein expression was significantly decreased by resveratrol pretreatment in a concentration-dependent manner compared with the $\mathrm{H}_{2} \mathrm{O}_{2}$ only group $(\mathrm{P}<0.05$; Fig. $4 \mathrm{~A}$ and $\mathrm{B})$. The results for the mRNA levels of caspase-3, PSGL-1 and VWF were similar to those observed for protein levels, although only a resveratrol concentration of $30 \mu \mathrm{M}$ was used (Fig. 4C).

Resveratrol suppresses the activation of PSGL-1 and VWF via MAPK signalling pathways. To investigate the underlying mechanisms of the effects of resveratrol on thrombosis-associated markers, the present study also detected the expression of MAPK signalling pathway-associated proteins and mRNA by western blotting and RT-qPCR, respectively. The mRNA levels of p38, ERK and c-Jun, and the protein levels of p-p38, P-ERK and P-c-Jun, were significantly increased by $\mathrm{H}_{2} \mathrm{O}_{2}$ compared with the control group ( $\mathrm{P}<0.05$; Figs. 5 and 6$)$. However, these increases were significantly decreased by pretreatment with $30 \mu \mathrm{M}$ resveratrol $(\mathrm{P}<0.05$; Figs. 5 and 6$)$. When HUVECs were exposed to anisomycin $(0.4 \mu \mathrm{g} / \mathrm{ml}$ for $6 \mathrm{~h})$, an activator of p38 and c-Jun, or curcumin ( $25 \mu \mathrm{M}$ for $4 \mathrm{~h})$, an activator of ERK, following treatment with resveratrol, the suppressive effects of resveratrol on PSGL-1 and VWF protein and mRNA expression were attenuated $\left(\mathrm{P}<0.05\right.$ vs. the $\mathrm{H}_{2} \mathrm{O}_{2}+$ resveratrol group; Figs. 5 and 6). In addition, anisomycin or curcumin treatment also significantly attenuated the effects of resveratrol treatment on the mRNA expression of p38, ERK and c-Jun, and the protein levels of p-p38, p-ERK and p-c-Jun $(\mathrm{P}<0.05$ vs. the $\mathrm{H}_{2} \mathrm{O}_{2}+$ resveratrol group; Figs. 5 and 6). However, no 


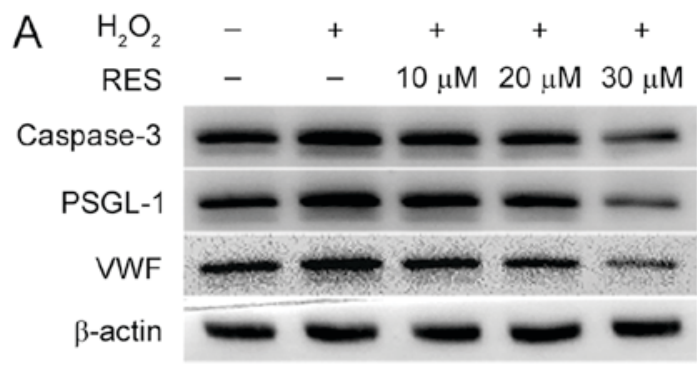

B

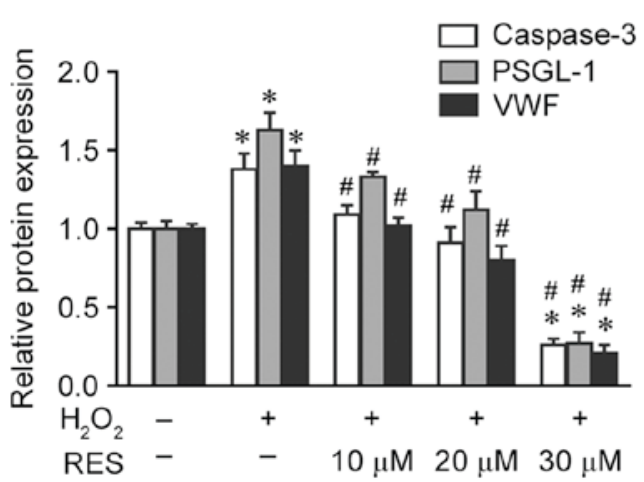

C

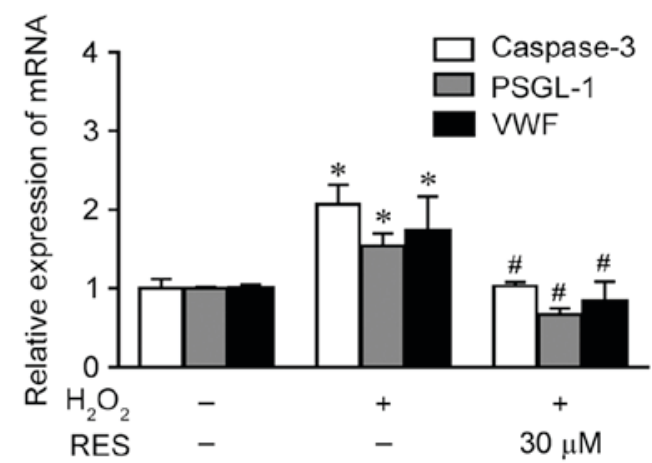

Figure 4. Resveratrol inhibits the protein and mRNA expression of caspase-3, VWF and PSGL-1 induced by $\mathrm{H}_{2} \mathrm{O}_{2}$ in $\mathrm{HUVEC}_{\mathrm{V}}$. (A) Protein expression levels of caspase-3, VWF and PSGL-1 in HUVECs exposed to $0,10,20$ and $30 \mu \mathrm{M}$ resveratrol for $2 \mathrm{~h}$ prior to treatment with or without $200 \mu \mathrm{M} \mathrm{H}_{2} \mathrm{O}_{2}$ for $24 \mathrm{~h}$, as measured by western blot analysis. $\beta$-actin was used as the loading control. (B) Relative expression ratios of caspase-3, VWF and PSGL-1 were determined by densitometric analysis. (C) mRNA expression of caspase-3, PSGL-1 and VWF in the different groups was investigated by reverse transcription-quantitative polymerase chain reaction. " $\mathrm{P}<0.05$ vs. control; ${ }^{*} \mathrm{P}<0.05$ vs. $\mathrm{H}_{2} \mathrm{O}_{2}$ only group. VWF, von Willebrand factor; PSGL-1, $\mathrm{P}$-selectin glycoprotein ligand-1; $\mathrm{H}_{2} \mathrm{O}_{2}$, hydrogen peroxide; HUVECs, human umbilical vein endothelial cells; RES, resveratrol.

significant differences were observed in the expression of total p38, ERK and c-Jun protein expression among the different groups (Fig. 5). These results indicate that resveratrol may suppress the activation of PSGL-1 and VWF induced by $\mathrm{H}_{2} \mathrm{O}_{2}$ via MAPK signalling pathways.

\section{Discussion}

DVT is a common postoperative complication following high-energy trauma that leads to localized clot (thrombus) formation within a femoral or popliteal vein. Venous ECs, platelets and leukocytes have crucial roles in regulating the local microenvironmental balance between coagulation and anticoagulation. Under normal physiological conditions, ECs maintain a vasodilatory and local fibrinolytic state, in which the coagulation, adhesion and activation of platelets and leukocytes is suppressed (22). Oxidative stress, defined as the excessive production of ROS and reactive nitrogen species, has been implicated in numerous diseases, including venous thrombosis. Under pathological conditions, excess ROS production is induced by venous stasis and hypoxia, which destroys endothelial structure and function, promotes procoagulation reactions by upregulating cell adhesion molecules (VWF and PSGL-1), inflammatory cytokines and antifibrinolytic substances (plasminogen activator inhibitor-1), and downregulates anticoagulants and fibrinolytic substances $(23,24)$.

Resveratrol, a potent antioxidant, was recently determined to suppress oxidative stress and decrease ROS generation; the study by Pan et al (25) demonstrated that resveratrol suppressed tumour necrosis factor- $\alpha$-triggered ROS generation in HUVECs. Additionally, Zhou et al (26) reported that resveratrol pretreatment significantly attenuated the detrimental effect of tert-butyl hydroperoxide on cell viability and apoptosis by inhibiting mitochondrial ROS generation in HUVECs. In addition, Zhang et al (27) reported that the effects of vinorelbine on cell apoptosis, intracellular ROS generation and intracellular superoxide dismutase activity were attenuated when ECV-304 human vascular endothelial cells were pretreated with resveratrol. To confirm these studies, in the present study, HUVECs were pretreated with resveratrol for $2 \mathrm{~h}$ and incubated with $\mathrm{H}_{2} \mathrm{O}_{2}$ for $24 \mathrm{~h}$. HUVEC viability was decreased significantly by $\mathrm{H}_{2} \mathrm{O}_{2}$, one of the major components of ROS. In addition, resveratrol protected cells from $\mathrm{H}_{2} \mathrm{O}_{2}$-induced cytotoxicity in a concentration-dependent manner, as demonstrated in Fig. 1. Furthermore, resveratrol significantly decreased ROS levels and clearly attenuated $\mathrm{H}_{2} \mathrm{O}_{2}$-induced apoptosis, as presented in Figs. 2 and 3. As sufficient evidence indicates that resveratrol may suppress oxidative stress and decrease ROS generation, resveratrol may have potential in the prevention of DVT.

VWF, which is produced by megakaryocytes and ECs, is a multimeric glycoprotein that is expressed in the subendothelial matrix, blood plasma, platelets and endothelium (28). VWF binds to exposed subendothelial collagen rapidly upon damage to the vascular surface and triggers a complex pathway, including platelet activation, adhesion and aggregation (29). 
A

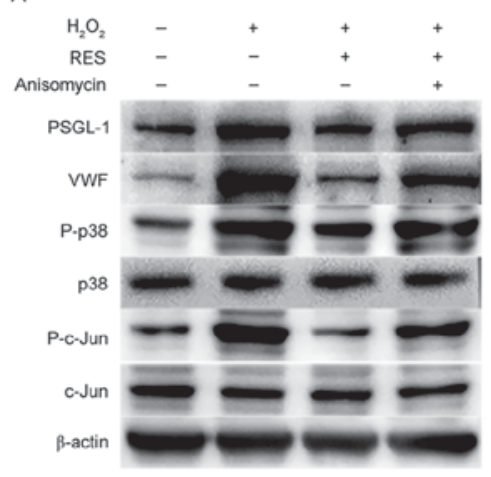

C

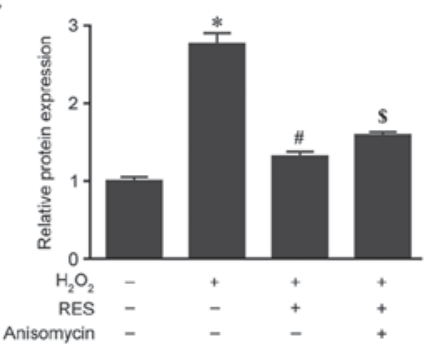

$\mathrm{E}$

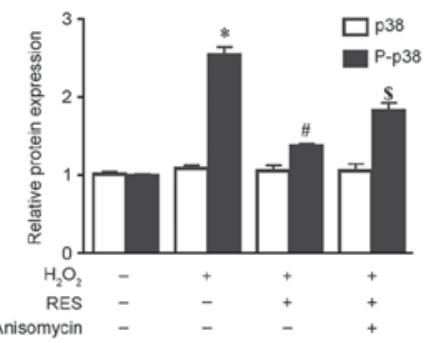

G
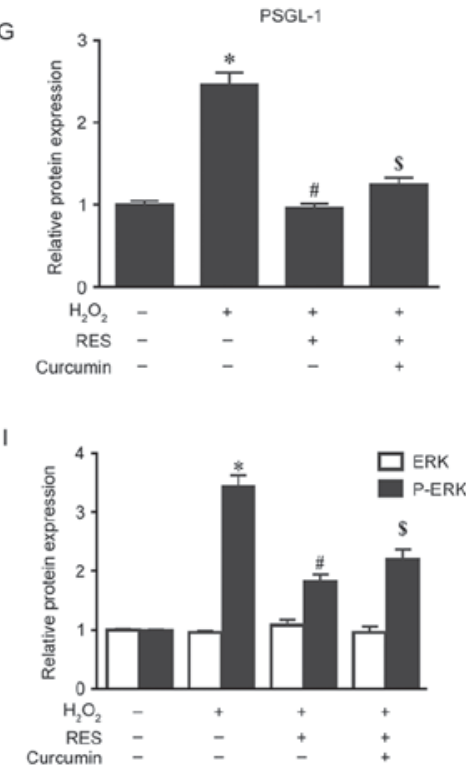

B

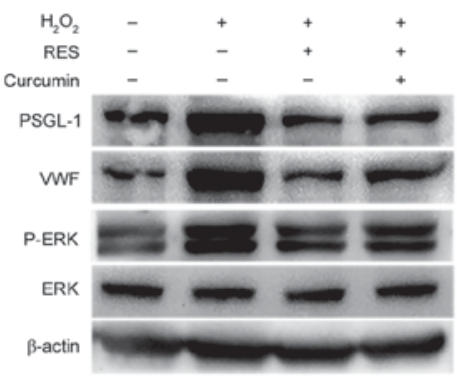

VWF

D

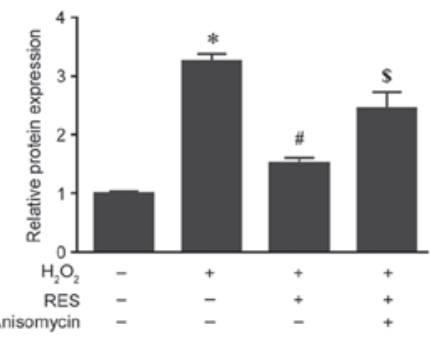

F

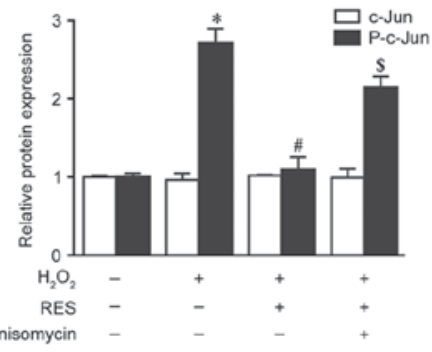

H

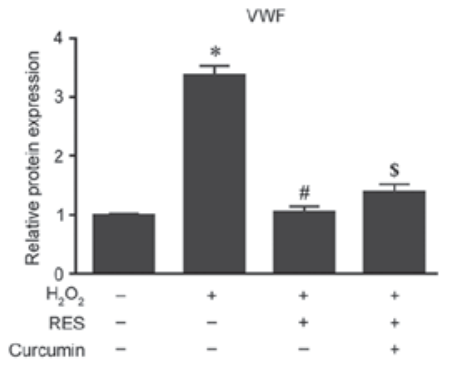

Figure 5. Resveratrol suppresses the protein expression of PSGL-1 and VWF induced by $\mathrm{H}_{2} \mathrm{O}_{2}$ via the mitogen-activated protein kinase signalling pathway. (A) Protein expression levels of PSGL-1, VWF, p-p38, p38, p-c-Jun and c-Jun in HUVECs exposed to $30 \mu \mathrm{M}$ resveratrol for $2 \mathrm{~h}$ and $0.4 \mu \mathrm{g} / \mathrm{ml}$ anisomycin for $6 \mathrm{~h}$ prior to treatment with $200 \mu \mathrm{M} \mathrm{H}_{2} \mathrm{O}_{2}$ for $24 \mathrm{~h}$ were measured by western blot analysis. (B) Protein expression levels of PSGL-1, VWF, p-ERK and ERK in HUVECs exposed to $30 \mu \mathrm{M}$ resveratrol for $2 \mathrm{~h}$ and $25 \mu \mathrm{M}$ curcumin for $4 \mathrm{~h}$ prior to treatment with $200 \mu \mathrm{M} \mathrm{H}_{2} \mathrm{O}_{2}$ for $24 \mathrm{~h}$ were measured by western blot analysis. $\beta$-actin was used as the loading control. The relative expression ratios of (C) PSGL-1, (D) VWF, (E) p-p38 and p-38, and (F) p-c-Jun and c-Jun, in cells treated with $\mathrm{H}_{2} \mathrm{O}_{2}$ with or without pretreatment with resveratrol and anisomycin were determined by densitometric analysis. The relative expression ratios of (G) PSGL-1, (H) VWF, and (I) P-ERK and ERK, in cells treated with $\mathrm{H}_{2} \mathrm{O}_{2}$ with or without pretreatment with resveratrol and curcumin were determined by densitometric analysis. "P<0.05 vs. control; ${ }^{*} \mathrm{P}<0.05$ vs. $\mathrm{H}_{2} \mathrm{O}_{2}$ only group; ${ }^{\$} \mathrm{P}<0.05$ vs. $\mathrm{H}_{2} \mathrm{O}_{2}+\mathrm{RES}$ group. PSGL-1, P-selectin glycoprotein ligand-1; VWF, von Willebrand factor; $\mathrm{H}_{2} \mathrm{O}_{2}$, hydrogen peroxide; p, phosphorylated; c-Jun, c-Jun N-terminal kinase; HUVECs, human umbilical vein endothelial cells; ERK, extracellular signal-regulated kinase; RES, resveratrol. 
A

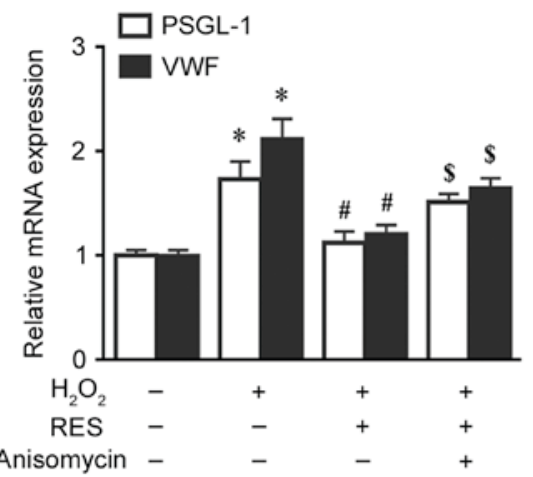

C

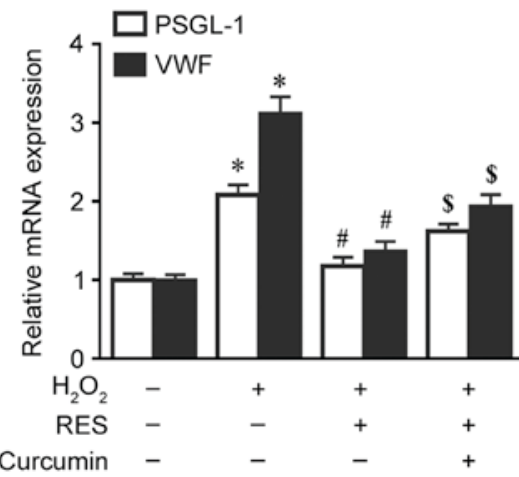

B

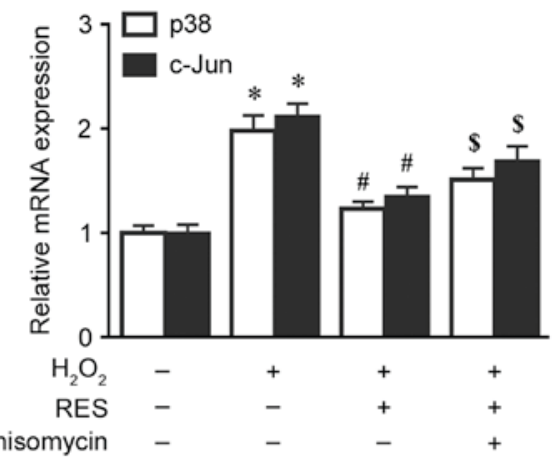

D

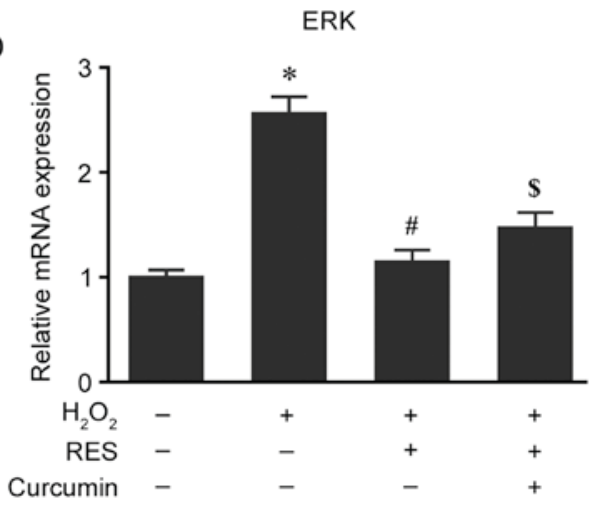

Figure 6. Resveratrol suppresses the mRNA upregulation of PSGL-1 and VWF induced by $\mathrm{H}_{2} \mathrm{O}_{2}$ via the mitogen-activated protein kinase signalling pathway. The relative mRNA expression levels of (A) PSGL-1 and VWF, and (B) p38 and c-Jun, in HUVECs exposed to $30 \mu \mathrm{M}$ resveratrol for $2 \mathrm{~h}$ and $0.4 \mu \mathrm{g} / \mathrm{ml}$ anisomycin for $6 \mathrm{~h}$ prior to treatment with $200 \mu \mathrm{M} \mathrm{H}_{2} \mathrm{O}_{2}$ for $24 \mathrm{~h}$ were measured by RT-qPCR. The relative mRNA expression levels of (C) PSGL-1 and VWF, and (D) ERK, in HUVECs exposed to $30 \mu \mathrm{M}$ resveratrol for $2 \mathrm{~h}$ and $25 \mu \mathrm{M}$ curcumin for $4 \mathrm{~h}$ prior to treatment with $200 \mu \mathrm{M} \mathrm{H}_{2} \mathrm{O}_{2}$ for $24 \mathrm{~h}$ were measured by RT-qPCR. " $\mathrm{P}<0.05$ vs. control; " $\mathrm{P}<0.05$ vs. $\mathrm{H}_{2} \mathrm{O}_{2}$ only group; ${ }^{\mathrm{S}} \mathrm{P}<0.05$ vs. $\mathrm{H}_{2} \mathrm{O}_{2}+\mathrm{RES}$ group. PSGL-1, $\mathrm{P}$-selectin glycoprotein ligand-1; VWF, von Willebrand factor; $\mathrm{H}_{2} \mathrm{O}_{2}$, hydrogen peroxide; c-Jun, c-Jun N-terminal kinase; HUVECs, human umbilical vein endothelial cells; RT-qPCR, reverse transcription-quantitative polymerase chain reaction; ERK, extracellular signal-regulated kinase; RES, resveratrol.

PSGL-1 is a glycoprotein that was originally identified in leukocytes as the ligand of P-selectin and has an important role in the selective recruitment of leukocytes and activated platelets into the venous wall, which amplifies the coagulation cascade and results in increased thrombin generation $(30,31)$. Consequently, VWF and PSGL-1 are referred to as thrombosis-associated markers, and increased levels of these markers in the plasma predicts the occurrence of thrombosis $(20,32)$. To validate the inhibitory effect of resveratrol on DVT in vitro, the present study investigated the effect of resveratrol on VWF and PSGL-1 in HUVECs. The results demonstrated that VWF and PSGL-1 secretion from the HUVECs was stimulated by $\mathrm{H}_{2} \mathrm{O}_{2}$, while resveratrol markedly decreased VWF and PSGL-1 elevation in a concentration-dependent manner, as demonstrated in Fig. 4. To the best of our knowledge, the present study is the first to investigate the effect of resveratrol on thrombosis-associated markers, and the results indicate that resveratrol may inhibit venous thrombosis by suppressing VWF and PSGL-1. However, it should be noted that this conclusion is only based on in vitro experiments and at the molecular level. Follow-up animal studies are required to confirm this hypothesis.

Various studies have reported that MAPK pathways contribute to vascular endothelial oxidative stress and venous thrombosis. The expression and secretion of VWF via the activation of ERK was blocked by inhibitors of ERK in HUVECs (33). Venous thrombosis triggered by PSGL-1 and P-selectin was reported to depend on MAPK signalling pathways (34). In the present study, the results demonstrated that $\mathrm{H}_{2} \mathrm{O}_{2}(200 \mu \mathrm{M})$ induced upregulation of mRNA and protein phosphorylation levels of p38, ERK and c-Jun in HUVECs, and resveratrol downregulated these effects at the mRNA and protein phosphorylation levels. When HUVECs were pretreated with the MAPK activators anisomycin and curcumin, the suppressive effects of resveratrol on PSGL-1 and VWF were attenuated, as demonstrated in Figs. 5 and 6. A studies reported that MAPKs cascades were maximally activated within 10-20 min after treatment with numerous stimuli (35). To investigate the simultaneous alterations in MAPKs with PSGL-1 and VWF, levels of p-p38, P-ERK and p-c-Jun were assayed after treatment with $\mathrm{H}_{2} \mathrm{O}_{2}$ for $24 \mathrm{~h}$. Due to this discrepancy and limitation of the present study, MAPK pathways should be assayed within $20 \mathrm{~min}$ to validate the results of the present study.

The results of the present study indicated that resveratrol may inhibit the activation of VWF and PSGL-1 via MAPK pathways. However, regarding the development of venous thrombosis, the underlying molecular mechanisms regulating the expression of VWF and PSGL-1 is complex and requires further investigation. In conclusion, these findings demonstrate that resveratrol may protect HUVECs from oxidative stress and apoptosis, and suppress the expression of thrombosis-associated markers, by inactivating MAPK signalling pathways. 


\section{Acknowledgements}

The present study was funded by the National Natural Science Foundation of China (grant no. 81160236) and the Health Science and Technology Project of Yunnan province (grant nos. 2014NS142 and 2017NS022).

\section{References}

1. Ashrani AA and Heit JA: Incidence and cost burden of post-thrombotic syndrome. J Thromb Thrombolysis 28: 465-476, 2009.

2. Dixon J, Ahn E, Zhou L, Lim R, Simpson D and Merriman EG: Venous thromboembolism rates in patients undergoing major hip and knee joint surgery at waitemata district health board: A retrospective audit. Intern Med J 45: 416-422, 2015.

3. Cha SI, Lee SY, Kim CH, Park JY, Jung TH, Yi JH, Lee J, Huh S, Lee HJ and Kim SY: Venous thromboembolism in Korean patients undergoing major orthopedic surgery: A prospective observational study using computed tomographic (CT) pulmonary angiography and indirect CT venography. J Korean Med Sci 25: 28-34, 2010.

4. Ho KM, Burrell M, Rao S and Baker R: Incidence and risk factors for fatal pulmonary embolism after major trauma: A nested cohort study. Br J Anaesth 105: 596-602, 2010.

5. López JA and Chen J: Pathophysiology of venous thrombosis. Thromb Res 123 (Suppl 4): S30-S34, 2009.

6. Kim YW and Byzova TV: Oxidative stress in angiogenesis and vascular disease. Blood 123: 625-631, 2014.

7. Ekim M, Sekeroglu MR, Balahoroglu R, Ozkol H and Ekim H: Roles of the oxidative stress and ADMA in the development of deep venous thrombosis. Biochem Res Int 2014: 703128, 2014.

8. Fan LM, Douglas G, Bendall JK, McNeill E, Crabtree MJ, Hale AB, Mai A, Li JM, McAteer MA, Schneider JE, et al: Endothelial cell-specific reactive oxygen species production increases susceptibility to aortic dissection. Circulation 129: 2661-2672, 2014

9. Zeng M, Wei X, Wu Z, Li W, Li B, Fei Y, He Y, Chen J, Wang P and Liu X: Reactive oxygen species contribute to simulated ischemia/reperfusion-induced autophagic cell death in human umbilical vein endothelial cells. Med Sci Monit 20: 1017-1023, 2014.

10. Yang Y, Duan W, Liang Z, Yi W, Yan J, Wang N, Li Y, Chen W, Yu S, Jin Z and Yi D: Curcumin attenuates endothelial cel oxidative stress injury through Notch signaling inhibition. Cell Signal 25: 615-629, 2013

11. Kostyuk VA, Potapovich AI, Suhan TO, de Luca C and Korkina LG: Antioxidant and signal modulation properties of plant polyphenols in controlling vascular inflammation. Eur J Pharmacol 658: 248-256, 2011.

12. Csiszár A, Csiszar A, Pinto JT, Gautam T, Kleusch C, Hoffmann B, Tucsek Z, Toth P, Sonntag WE and Ungvari Z: Resveratrol encapsulated in novel fusogenic liposomes activates Nrf2 and attenuates oxidative stress in cerebromicrovascular endothelial cells from aged rats. J Gerontol A Biol Sci Med Sci 70: 303-313, 2015.

13. Brisdelli F, D'Andrea G and Bozzi A: Resveratrol: A natural polyphenol with multiple chemopreventive properties. Curr Drug Metab 10: 530-546, 2009.

14. Guo H, Chen Y, Liao L and Wu W: Resveratrol protects HUVECs from oxidized-LDL induced oxidative damage by autophagy upregulation via the AMPK/SIRT1 pathway. Cardiovasc Drugs Ther 27: 189-198, 2013.

15. Hu YX, Cui H, Fan L, Pan XJ, Wu JH, Shi SZ, Cui SY, Wei ZM and Liu L: Resveratrol attenuates left ventricular remodeling in old rats with COPD induced by cigarette smoke exposure and LPS instillation. Can J Physiol Pharmacol 91: 1044-1054, 2013.

16. Lan F, Weikel KA, Cacicedo JM and Ido Y: Resveratrol-induced AMP-Activated protein kinase activation is cell-type dependent: Lessons from basic research for clinical application. Nutrients 9: E751, 2017.
17. Abdel-Aleem GA, Khaleel EF, Mostafa DG and Elberier LK: Neuroprotective effect of resveratrol against brain ischemia reperfusion injury in rats entails reduction of DJ-1 protein expression and activation of PI3K/Akt/gsk3b survival pathway. Arh Physiol Biochem 122: 200-213, 2016.

18. Adam F, Kauskot A, Rosa JP and Bryckaert M: Mitogen-activated protein kinases in hemostasis and thrombosis. J Thromb Haemost 6: 2007-2016, 2008.

19. Lazzari MA, Sanchez-Luceros A, Woods AI, Alberto MF and Meschengieser SS: Von Willebrand factor (VWF) as a risk factor for bleeding and thrombosis. Hematology 17 (Suppl 1): S150-S152, 2012.

20. Miszti-Blasius K, Debreceni IB, Felszeghy S, Dezso B and Kappelmayer J: Lack of P-selectin glycoprotein ligand-1 protects mice from thrombosis after collagen/epinephrine challenge. Thromb Res 127: 228-234, 2011.

21. Livak KJ and Schmittgen TD: Analysis of relative gene expression data using real-time quantitative PCR and the 2(-Delta Delta C(T)) Method. Methods 25: 402-408, 2001.

22. Bertina RM: The role of procoagulants and anticoagulants in the development of venous thromboembolism. Thromb Res 123 (Suppl 4): S41-S45, 2009.

23. Violi F and Pignatelli P: Platelet oxidative stress and thrombosis. Thromb Res 129: 378-381, 2012.

24. Wakefield TW, Myers DD and Henke PK: Role of selectins and fibrinolysis in VTE. Thromb Res 123 (Suppl 4): S35-S40, 2009.

25. Pan W, Yu H, Huang S and Zhu P: Resveratrol protects against TNF- $\alpha$-induced injury in human umbilical endothelial cells through promoting sirtuin-1-induced repression of NF-KB and p38 MAPK. PLoS One 11: e0147034, 2016.

26. Zhou X, Chen M, Zeng X, Yang J, Deng H, Yi L and Mi MT: Resveratrol regulates mitochondrial reactive oxygen species homeostasis through Sirt3 signaling pathway in human vascular endothelial cells. Cell Death Dis 5: e1576, 2014.

27. Zhang J, Tong N, Chen Y, Li P, Yang S and Zhao X: Resveratrol protects against vinorelbine-induced vascular endothelial cell injury. Toxicol Mech Methods 23: 665-671, 2013.

28. Matsui $\mathrm{T}$ and Hamako J: von Willebrand factor and von Willebrand disease. Rinsho Ketsueki 57: 2113-2123, 2016.

29. Castaman G and Linari S: Human von Willebrand factor/factor VIII concentrates in the management of pediatric patients with von Willebrand disease/hemophilia A. Ther Clin Risk Manag 12: 1029-1037, 2016.

30. Cerletti C, Tamburrelli C, Izzi B, Gianfagna F and de Gaetano G: Platelet-leukocyte interactions in thrombosis. Thromb Res 129: 263-266, 2012.

31. Hubert L, Darbousset R, Panicot-Dubois L, Robert S, Sabatier F, Fallague K, Dignat-George F and Dubois C: Neutrophils recruit and activate human endothelial colony-forming cells at the site of vessel injury via P-selectin glycoprotein ligand-1 and L-selectin. J Thromb Haemost 12: 1170-1181, 2014.

32. Lazzari MA, Sanchez-Luceros A, Woods AI, Alberto MF and Meschengieser SS: Von Willebrand factor (VWF) as a risk factor for bleeding and thrombosis. Hematology 17 (Suppl 1): S150-S152, 2012

33. Wang J, Li H, He J, Li B, Bao Q, Zhang X, Lv Z, Zhang Y, Han J, Ai D and Zhu Y: 20-Hydroxyeicosatetraenoic acid involved in endothelial activation and thrombosis. Am J Physiol Heart Circ Physiol 308: H1359-H1367, 2015

34. Zuchtriegel G, Uhl B, Puhr-Westerheide D, Pörnbacher M, Lauber K, Krombach F and Reichel CA: Platelets guide leukocytes to their sites of extravasation. PLoS Biol 14: e1002459, 2016.

35. Gao H, Liu L, Zhao Y, Hara H, Chen P, Xu J, Tang J, Wei L, Li Z, Cooper DK, et al: Human IL-6, IL-7, IL-1 $\beta$, and TNF- $\alpha$ differently regulate the expression of pro-inflammatary related genes, tissue factor, and swine leukocyte antigen class I in porcine aortic endothelial cells. Xenotransplantation 24: e12291, 2017. 